\title{
Workplace requests: A critical literature review
}

Neil Lapierre ${ }^{1}$

\begin{abstract}
Workplace literacies is an area that has attracted a growing number of researchers. Being workplace literate, or being able to use appropriate language and types of communication in a new workplace, is a difficult task for many new employees, especially those whose first language is different from the one used at work (MURPHY, 2010). Requests as a type of workplace communication can pose additional challenges because of their facethreatening nature (BROWN; LEVINSON, 1987). This review synthesizes literature on such types of workplace communication as oral requests and request e-mails. Key theoretical underpinnings of research on requests in the workplace, conventions and features of e-mail, request strategies based on levels of directness, and supportive moves that mitigate requests are discussed. Differences between oral requests and request e-mails in the workplace are found, and pedagogical implications are provided.
\end{abstract}

Keywords: politeness strategies; request; workplace; e-mail; English for specific purposes.

\section{Solicitações em ambiente de trabalho: Uma resenha crítica da literatura}

\section{Resumo}

Ser letrado para o ambiente de trabalho, ou ser capaz de usar tipos de textos apropriados (BIBER, 1988), ou tipos de comunicação, em um novo ambiente de trabalho é uma tarefa difícil para muitos novos empregados, especialmente para aqueles cuja língua primeira é diferente daquela usada no trabalho (MURPHY, 2010). Solicitações/Requisições são um tipo de comunicação no ambiente de trabalho que pode colocar desafios adicionais em função de sua natureza frequentemente ameaçadora (BROWN; LEVINSON, 1987). Esta resenha sintetiza a literatura sobre tais tipos de comunicação em ambiente de trabalho como requisições orais e e-mails de requisição. Com fundamentações teóricas chave baseadas em pesquisa sobre requisições em ambiente te trabalho, convenções e características de e-mail, estratégias de requisição pautadas por níveis de honestidade, e movimentos de apoio que mitigam requisições são discutidas. Diferenças entre requisições orais e e-mails de solicitação no ambiente de trabalho são encontradas, e implicações pedagógicas são providas.

Palavras-chave: estratégias de polidez; requisições; ambiente de trabalho; e-mail; inglês para fins específicos.

1 Universidade de Carleton, Ottawa, neillapierre@cmail.carleton.ca

Periódico Horizontes - USF - Itatiba, SP - Brasil - e020003 


\section{Introduction}

Understanding what appropriate language and communication types to use when entering a new workplace can pose a challenge to new employees. This is especially true for employees whose first language (L1) is different from the language used in the work setting (MURPHY, 2010). Using appropriate language is often a key determining factor in how our colleagues perceive us (WIGGLESWORTH; YATES, 2007) (YATES 2010a) and how successfully we fit into the social aspect of work. The ability to participate in this critical component of work is just as important as being able to complete required tasks in order to be successful at work (HOLMES, 2005). Requests - when a speaker wants a hearer to complete an action or share information - are necessary in the workplace $(\mathrm{HO}, 2018)$ but the imposing nature of requests may make them difficult to form (LEOPOLD, 2015) (YATES, 2010b). E-mails that are primarily sent to make a request, also called request e-mails, have been reported as intimidating for some employees in a new work setting (LEOPOLD, 2015). Having knowledge of all the different forms and mitigation devices that make an utterance (BAKHTIN, 1986) realized as a request or pragmalinguistic conventions of requests - is useful when forming requests. But the requester must also have sociopragmatic competence - the ability to use appropriate language for a situation in a particular setting - in order to apply the pragmalinguistic conventions of requests in a successful way that is perceived as appropriate by others.

This review considers a successful request to be one wherein the requestee fulfills the request and the relationship between the requester and requestee sustains minimal or no damage. The oral or written request must also be immediately understood by the requestee, who needs to realize that a request is being made and what is being requested. As Hyland (2007) observes, readers can typically anticipate the purpose of a text by making connections to previous texts within the same genre, and a writer can make the job of a reader easier if the writer can anticipate the reader's expectations of a certain text. This view echoes the notion that pragmalinguistic conventions are essential in forming requests (HYLAND, 2007).

Pragmalinguistic conventions for requests vary across different workplaces, so it would be inappropriate to teach language learners one standard type of requests for all workplaces. 
Language learners need to be able to form requests and understand requests within their specific workplace contexts. Street (2003) asserts that autonomous literacy, where a learner can improve their current economic situation through literacy skills training, does not take different contexts into account and thus may displace conceptions of literacy from one class onto another, or from a western perspective onto non-western cultures (p.77). For this reason, studies that take into consideration specific workplace contexts may provide a more productive ideological approach to literacy.

\section{Aim and research questions}

Keeping these considerations in mind, the aim of this literature review is to synthesize results from studies on oral requests and (written) request e-mails in workplace contexts to determine if the pragmalinguistic conventions found in oral requests resemble pragmalinguistic conventions found in request e-mails. One motivation for this is to have a better understanding of how requests in the workplace can be taught to newcomers with a different L1 than the one spoken at their workplace. There is already a substantial amount of research that has found that explicit (eg. SYKES, 2009) (HALENKO; JONES, 2011) and implicit teaching (eg. FUKUYA; HILL, 2006) (SYKES, 2009) of pragmalinguistic conventions have positive effects on participants' posttests scores in interventional studies. This review works under the assumption that if teaching pragmalinguistic conventions for oral requests in the workplace can be beneficial to a language learner's sociopragmatic competence and their workplace literacy, then knowledge of the pragmalinguistic conventions found in request e-mails is also likely to be beneficial for language learners who need to understand and make requests at work through e-mail. However, that does not necessarily mean that explicit teaching of pragmalinguistic conventions found in oral requests can help a newcomer compose an appropriate request e-mail. It would only be useful if the pragmalinguistic conventions and the frequency of those conventions are identical in oral requests and request e-mails (citation is needed here). Thus, this review seeks responses to the following research questions:

1. What politeness strategies are found in the literature on oral requests in English-speaking workplaces?

Periódico Horizontes - USF - Itatiba, SP - Brasil - e020003 
2. What politeness strategies are found in the literature on request e-mails in English- speaking workplaces?

3. Do the politeness strategies of oral request and request e-mails differ in English- speaking workplaces, and if so, what are those differences?

In order to answer these three questions, this review outlines the key theoretical underpinnings of much of the research on requests in the workplace, the categorization and purpose of e-mails in the workplace, levels of directness found in workplace requests, internal and external modifications of requests, insights enriched through context, and unique features found in request e-mails.

\section{Underpinnings of research on workplace requests Pragmatics and Politeness}

Much of the research on requests is based in pragmatics - the study of how language is used - which builds on the work of Austin (1975). According to Austin (1975), an utterance has (a) locution, or the actual meaning of each word in the utterance, (b) illocution, or the intended impact the speaker wants to have on the world through their utterance, and (c) perlocution, or the actual real life impact the utterance has and how the utterance is received by others. Considering this, Searle (1979) coined the term speech act to define an utterance said with intention. Speech acts are generally accepted to be universal in different languages but the manner in which a speech act is formed by a speaker and realized by a hearer vary greatly among different languages, different regions and different cultures (YATES, 2010a). Further, in this review, we use the notion of the "text type", or "type of communication", to refer to the types of requests discussed. As requests significantly vary from one context to another, we have chosen to avoid the term "genre" in relation to requests.

Another theory widely used in research on requests is Politeness theory (BROWN; LEVINSON, 1987). In politeness theory, Brown and Levinson (1987) state that for requests, linguistic choices are made based on (a) social distance, (b) power relationships, and (c) the level of imposition that the request has on the requestee. Brown and Levinson (1987) also 
introduced the notion of face. Face is defined as the public self-image, and care must be taken to "keep face" in an interaction between the interlocutors. Positive face strategies are used to make the hearer feel closer to the speaker or boost the hearer's sense of their own face (BROWN; LEVINSON, 1987). Negative face strategies are used to make the speaker know that the hearer does not want to impede on their autonomy, or to minimize the imposition of the utterance (BROWN; LEVINSON, 1987). According to Brown and Levinson (1987), requests represent a face-threatening act as they can lower both parties' positive face. For example, some requests may make the speaker seem incompetent or demanding and, with unfulfilled requests, the hearer may seem uncooperative (YATES, 2010a). Requests can also lower the negative face of the hearer, as it impedes their autonomy. Requests may seem intimidating to construct, especially if the requester is not aware of the pragmalinguistic conventions they can use, because requests are a face-threatening act.

It should be noted that even though both the notion of speech acts (SEARLE, 1979) and politeness theory (BROWN; LEVINSON, 1987) were developed for oral communication, both have been applied to research on written requests, specifically, request e-mails (eg. BREMNER, 2006) (CALLAHAN, 2011).

\section{Cross Cultural Speech Act Realization Project}

The Cross-Cultural Speech Act Realization Project (CCSARP) is a large multi-study project that looks at how speech acts are discursively constructed and realized in different languages and dialects (BLUM-KULKA; KASPER; HOUSE, 1989). The CCSARP Coding Manual - a framework for identifying and describing the requests - has been widely used in studies on oral requests (BLUM-KULKA; OLSHTAIN, 1984) (FAERCH; KASPER, 1989). This Manual considers the work of Austin, Searle and politeness theory to determine the pragmalinguistic conventions that help to realize a request and compare the socially acceptable manner a request is constructed throughout different cultural contexts (BLUM-KULKA; KASPER; HOUSE, 1989). The purpose of the CCSARP Coding Manual is to provide researchers with a way to more accurately identify and describe speech acts when using discourse completion tasks, and to be used as a tool for language teachers to understand the pragmalinguistic conventions of those speech acts to pass 


\section{HSE}

on to their students.

The CCSARP Coding Manual divides requests into a head act, alerters, and supportive moves 2. Each request has one head act and may or may not contain supportive moves or alerters. The head act is the smallest unit that can be uttered to have a request realized. As Blum-Kulka, Kasper and House (1989) state, the head act "is the core of the request sequence" (p.275). Many studies such as Leopold (2015), Ross (2018) and Kong (2006) have used this notion of a head act to analyze requests in two parts: the request, and supporting moves. This approach allows researchers to investigate what the actual request is and what requesters add to the request to make it less threatening.

The CCSARP Coding Manual (BLUM-KULKA; KASPER; HOUSE, 1989) also presents different strategies based on the request level of directness. These strategies are categorized into three broad groups: (a) direct, (b) conventionally indirect, and (c) unconventionally indirect. According to Blum-Kulka, Kasper and House (1989), the directness of a request is determined by how apparent the locution (i.e., the actual meaning) of the head act is to the requester's illocutionary intent (i.e., what the requester wants to happen). A head act can only be realized through a single request strategy. The choice of the level of directness is determined by politeness (BLUM-KULKA; KASPER; HOUSE, 1989). The CCSARP Coding Manual also includes classification of internal modification devices used in requests such as lexical mitigation and syntactic mitigation found in some head acts and provides classification of external modification devices found in the supportive moves, such as grounders, which provide reasons and justification for a request.

Like the speech act theory (SEARLE, 1979) and politeness theory (BROWN; LEVINSON, 1987), the CCSARP Coding Manual (BLUM-KULKA; KASPER; HOUSE, 1989) was initially developed for oral requests but has been applied to other types of requests such as e-mail (eg. LEOPOLD, 2015).

\section{Directness}

\section{Newcomers' Oral Requests}

Although the same speech acts are common to all languages, the way in which they are 
carried out in different settings varies drastically (BLUM- KULKA; KASPER; HOUSE, 1989) (YATES, 2010a), which is one of the reasons we abandon the term "genre" in favour of "communication type" in this paper. For example, the level of directness can vary significantly among requests and can be categorized into three strategies: direct requests (such as obligations, performatives, imperatives and elliptical phrases), conventionally indirect requests (such as query preparatory and want or need statements), and unconventionally indirect requests (such as hints). Conventionally indirect requests contain the most strategies and have been divided into separate categories by some researchers who have modified the CCSARP Coding Manual framework. Trosborg (1995), for example, altered the request strategy framework to a scale of least direct to most direct. In her scale, Trosborg (1995) separates conventionally indirect requests into two categories: (1) speaker-based conventionally indirect and (2) hearer-oriented conventionally indirect. Speaker-based strategies include wishes, desires and needs. Heareroriented strategies include asking for permission, inquiring about the hearer's abilities or willingness, and requests framed as suggestions. In her scale, Trosborg (2008) claims speakeroriented strategies are more direct than hearer-oriented strategies, which might explain why some studies that use the CCSARP Coding Manual to categorize requests consider speakeroriented strategies, such as want statements, direct while hearer-oriented strategies are categorized as indirect (eg. LEOPOLD, 2015) (YATES, 2010a).

Some studies classify conventionally indirect strategies with a high level of directness as direct (LI, 2000) (WIGGLESWORTH; YATES, 2007) (YATES, 2010a). Similarly to Trosborg (1995), Wigglesworth and Yates (2007) consider these two levels of directness, apparently assertive, which the authors consider direct, and negotiable or advisory, which the authors consider indirect. Wigglesworth and Yates (2007) place statements of desire or need, a conventionally indirect strategy according to the CCSARP Coding Manual, into the most direct category, apparently assertive. The study involves requests made by native speakers of English (NES) in an Australian workplace context through a simulated role-play. The Australian setting may provide insight into why conventionally indirect strategies were placed into the most direct category, as statements of desire or need may be perceived as a particularly assertive strategy.

Yates (2010a) expanded on the data from Wigglesworth and Yates (2007) by running the same role-plays with two more groups, non-native speakers of English (NNES), and a group of 
Dinka-background refugees from South Sudan. This mixed methods study was motivated by the difficulty some Dinka-background refugees were having in the Australian workplace. Employers and co-workers of these refugees were starting to develop stereotypes about the Dinkabackground workers being insistent and abrupt (YATES, 2010a, p.144). Yates found the Dinkabackground group made more want statements, an apparently assertive strategy, than the other two groups. The apparently assertive quality of the Dinka-background group's requests may provide an explanation as to why this group was being perceived as abrupt and insistent.

In a longitudinal qualitative case study on requests in the workplace, Li (2000) followed a Chinese immigrant, Ming, in the North-Eastern United States and investigated her levels of directness when making requests. Li served as a volunteer at an immigrant job training program and worked privately with Ming as an English workplace language tutor during the study. While a great number of studies on oral requests in general contexts and in the workplace use discourse completion tasks or role-plays (eg. BLUM-KULKA; KASPER; HOUSE, 1989) (BLUM- KULKA; OLSHTAIN, 1984) (FUKUYA; HILL, 2006) (HALENKO; JONES, 2011)(SYKES, 2009)(HOLMES; RIDDIFORD, 2011) (ROSS, 2018) (WIGGLESWORTH; YATES, 2007) (YATES, 2010a), Li (2000) took a different approach, by having Ming and people she frequently spoke to report on how she had made requests, and to detail the context surrounding that request. The reports were made from three participants: Ming, Ming's co-worker, and a director of the immigrant job training program. At the start of the study, Ming did not actively make requests or express her needs or wants to people at the immigrant job training program, but only provided information surrounding her problems.

Li (2000) departed from the coding system provided by the CCSARP Manual and divided requests into two categories: (a) direct and (b) indirect. Although Li (2000) referred to many of Ming's requests as indirect, they appeared to be hints, an unconventionally indirect request strategy found in the CCSARP Coding Manual. Ming initially used such hints as her main strategy for making requests. For example, when Ming wanted assistance and advice on how to get a job interview, she told the director of the immigrant job training program that her parents expected her to get a job to help support her family. The director reported having a difficult time determining that Ming wanted help. Li (2000) believed that to be because of Ming's work experiences in China and because of a negative transfer of pragmalinguistic conventions from 
her L1 and previous work experiences. Often LLs are unaware that they make assumptions based on appropriate ways to form requests in their L1 (YATES, 2010a).

Whereas Yates (2010a) discovered that the Dinka-background group might be more direct than their NES workplace counterparts, Li (2000) believed Ming to be initially too indirect with her requests. The Yates's (2010a) and Li's (2000) studies took place in different countries, with participants who had different backgrounds and work experiences, and the studies used different methods of collecting requests data. Regardless of these differences, it appears that when employees enter a workplace in a new country that uses a different language than their L1, they may struggle to find the appropriate level of directness due to a lack of knowledge of workplace culture, communication conventions and pragmalinguistic forms, and due to a low level of sociopragmatic competence in their new environment.

Many studies that use the CCSARP Coding Manual find that most English requests are formed using conventionally indirect request strategies (eg. BLUM-KULKA; HOUSE, 1989) (TROSBORG, 1995). Few quantitative studies have investigated workplace request directness of NES, but the empirical evidence of those few suggests the most common level of directness for oral requests in the workplace is hearer oriented conventionally indirect (ROSS, 2018); that is, common requests use negotiable or advisory indirect strategies (WIGGLESWORTH; YATES, 2007). Neither Ming (LI, 2000) nor the Dinka-background group (YATES, 2010a) used conventionally indirect requests frequently. While a conventionally indirect request is not always the most appropriate at any workplace, knowing that conventionally indirect requests are the most frequent type of oral request in many English-speaking workplaces could prove valuable to LLs.

\section{E-mail Requests Written by Native English Speakers}

A lack of authentic examples of workplace request e-mails had led Leopold (2015) to create a corpus of professional request e-mails. Leopold (2015) collected 205 request e-mails from 18 different industries including education, administration, and finance. Leopold (2015) used the CCSARP Coding Manual to categorize request strategies and request types used in the corpus. The emails contained a total of 450 head acts. It was found that $71.55 \%$ of requests 
used direct strategies, which, for Leopold (2015), include speaker-based conventionally indirect strategies (cf. WIGGLESWORTH; YATES, 2007) (YATES, 2010a) (TROSBORG, 1995). Indirect head acts for Leopold (2015) would only include hearer-oriented conventionally indirect strategies. This contrasts with the finding of workplace oral request research wherein the NES typically use hearer-oriented conventionally indirect strategies in simulations (e.g., ROSS, 2018) (WIGGLESWORTH; YATES, 2007). Imperatives, which are classified in the CCSARP Coding Manual as a direct request strategy, were the most common strategy found in Leopold's (2015) sample, with 155 imperatives in the corpus of 450 head acts, which appears to contrast with the findings of some quantitative workplace oral request studies that used simulations (e.g., ROSS, 2018) (WIGGLESWORTH; YATES, 2007). Query preparatory, which Ross (2018) found to be by far the most common oral request strategy found in her study, was the second most common request strategy in Leopold's (2015) findings, with 84 examples. Leopold (2015) found only 15 examples of unconventionally indirect strategies such as hints.

\section{Internal and external modifications of requests in the workplace}

Various devices can be used to modify the head act, often to soften the request. If the device is found within the head act, it is considered an internal modification. The CCSARP Coding Manual separates internal modification into two categories, lexical mitigation and syntactic mitigation (BLUM-KULKA; KASPER; HOUSE, 1989). If the device is found outside of the head act, it is considered an external modification. External modification devices act as supportive moves that work with the directness strategy, and internal modifications to form a successful request. Studies that have investigated these modifications are outlined in this section.

\section{Lexical Mitigation}

A common way to soften request is through lexical mitigation devices. These devices include politeness markers, hedges, and interpersonal markers. Lexical mitigation devices are often found within the head act. The use of lexical mitigation varied greatly between the two groups investigated in Yates's (2010a) study, Australian NES and Dinka-background group. In 
role plays, the Dinka-background group used a total of 107 lexical mitigation devices, whereas the NES participants used 296, which is a significantly higher number. The lack of knowledge of pragmalinguistic and rhetorical conventions and the lexical mitigation devices may explain the Dinka-background group's less frequent use of the lexical mitigation devices. Both groups exhibited examples of each lexical mitigation device (YATES, 2010a) but the Dinka-background group would have had less exposure to each device and were less likely to use the devices in a role play situation. Negative transfer from L1 request conventions may also contribute to these participants' lower level of sociopragmatic competence in their new environment.

Yates (2010a) did not report any politeness markers as a form of mitigation in her study, which echoes Ross's (2018) findings that only $1.1 \%$ of the requests in her corpus of workplace request discourse completion tasks contained the word "please," a common politeness marker. This is especially surprising when compared to the studies that look at workplace request emails in a North American setting; for example, Leopold (2015) found the politeness marker "please" to occur in over two thirds of the head acts that contained imperatives in her corpus of authentic professional request e-mails from American organizations. Similarly, Callahan (2011) found instances of "please" used in request e-mails from all the participants in her study, with Jane, a subordinate in the study, using "please" as a politeness marker more often than her supervisors (CALLAHAN, 2011), which may be explained by the politeness theory assumption that requesters with inherent power over the requestees can form requests using less politeness strategies and still be successful in their request (BREMNER, 2006).

\section{Syntactic Mitigation}

In English, requests can be softened through syntactic mitigation devices which include using modals (can, might, would, could), past tense marking (was, wanted, hoped), the continuous (hoping, wondering, wanting), and embedded if clauses ("I was just wondering if it would be possible..."). A requester is not limited to one of these syntactic mitigations and can use a combination of two or more. For example, Wigglesworth and Yates (2007) suggest that in an Australian workplace context, NES frequently make use of syntactic mitigation devices. Yates (2010a) suggests that NES make more frequent use of these devices than both the mix- 


\section{HSE}

background NNES and the Dinka-background group.

In another study, Holmes and Riddiford (2011) followed Helena, a newcomer to New Zealand, who had a high proficiency in English. When given the task of asking a lower level employee to stay late in a role-play, Helena used a lexical mitigation device, hedges, to soften the language. Helena's request was refused in this role-play which Helena and other participants described as "shocking" (p.381). When Helena completed the same role-play 12 weeks after the initial one (HOLMES; RIDDIFORD, 2011), she formed her request by first setting up context, followed with "I was wondering if you can..." (p. 382). Here, Helena incorporated the syntactic mitigation devices, embedding, modals and the continuous tense. She reported that "wondering" is a "magic word" that allows for more negotiation on the part of the requestee. At the end of the 12 weeks, Helena used a wider range of pragmalinguistic conventions when making requests in role-plays, incorporating various internal modification devices such as lexical mitigation and syntactic mitigation. After the final role-play, Holmes; Riddiford (2011) observed Helena's use of the phrase "I was wondering if you could" (p.383) in a real-world situation where Helena was forming a request at her actual workplace. Helena also reported being aware of the syntactic mitigation used by her superior which gave her a much better understanding of what was expected of her in the workplace.

\section{External modifications}

A request can be made to seem more appropriate by use of supportive moves found before or after the head act (BLUM-KULKA; KASPER; HOUSE, 1989). These supportive moves are referred to as propositional mitigation (WIGGLESWORTH; YATES 2007) (YATES, 2010a), external modification (ROSS, 2018), or accounts (KONG, 2006). The CCSARP Coding Manual provides the six supportive moves meant to mitigate a request: (a) preparators, (b) getting precommitments, (c) grounders, (d) disarmers,(e) promises of reward, and ( $f$ ) imposition minimizers (BLUM- KULKA; KASPER; HOUSE, 1989). A grounder, or a reason, explanation, or justification (BLUM- KULKA; KASPER; HOUSE, 1989) paired with the head act of a request, serves as a negative face politeness strategy because providing a grounder allows the requestees to use their own sense of logic to respond, thus allowing them an opportunity to be 
autonomous (KONG, 2006). All the reviewed studies that investigated supportive moves in workplace requests found grounders to be the most frequent type of external modification (KONG, 2006) (ROSS, 2018) (WIGGLESWORTH; YATES; 2007) (YATES 2010a).

Kong (2006) looked exclusively at the external modifications of directives (where a directive, according to Searle (1979), is an utterance spoken with the intention to have the hearer complete an action) found in 250 English e-mails in Hong Kong workplaces. Kong (2006) divided the e-mails into three categories based on the power relationship of the requester in relation to the requestee as (a) subordinate to superior, (b) superior to subordinate, and (c) between peers, and found that subordinates used the most external modifications in their directive e-mails while directives sent between equals in the corpus used the least amount of external modifications. The finding that subordinates used more external modifications is in line with Brown and Levinson's (1987) politeness theory and other research that has looked at e- mail requests and power relationships (BIESENBACH-LUCAS, 2007) (BREMNER, 2006) (CALLAHAN, 2011). However, the observation that directives in e-mails between peers contain fewer external modification devices than e-mails sent by superiors conflicts with the findings that the higher the level of inherent power held, the less need there is for mitigation in requests (BREMNER, 2006) (CALLAHAN, 2011). Furthermore, e-mails between equals within some workplace environments tended to use more politeness strategies, as peers were in competition with each other so requests might seem even more threatening (FRAGALE et al., 2012). These discrepancies might be explained by two factors: Kong (2006) looked only at the external modification of the directives and did not investigate the lexical and syntactic mitigation devices in the head act. Also, all the request e-mails were in the context of Hong Kong workplaces that used English, which may have different request conventions than workplaces in countries that use English as L1.

\section{Insights from context}

Many of the studies in this review lack a careful consideration of context. Oral requests were often collected during simulations (eg. HOLMES; RIDDIFORD, 2011) (ROSS, 2018) (WIGGLESWORTH; YATES, 2007) and only minimal information was supplied in the studies of 
request e-mails (KONG, 2006) (LEOPOLD, 2015). However, Li (2000) was able to provide contextual information about her main participant, Ming, and the situation that the participant was experiencing. Through the interviews with Ming's co-worker and the director of the immigrant job training program as well as Li's (2000) own reflection on Ming's workplace literacy as her tutor, Li was able to provide explanations as to how Ming was perceived by some of the people she interacted with. Even though the context that Li provided was minimal, it shed some light on an apparently typical difficulty of forming requests experienced by Chinese women-immigrants in English-speaking workplaces. These immigrants often possess only limited knowledge of pragmalinguistic forms and socio-cultural and rhetorical conventions of workplace communication in an environment with very different sociopragmatic expectations and in a second language. From Li's study, we can see Ming's general position as an immigrant and the discrimination she faces in the workplace. It is reported in the study that Ming is eventually able to form a request in a real-life situation when she feels that her NES co-workers are disrespecting her and other NNES employees.

A small corpus of authentic request e-mails with comprehensive descriptions was presented in a study by Bremner (2006). Bremner collected request e-mails sent between employees within a Middle Eastern English-medium university over the course of a year. The emails were collected during the second stage of a multi-stage process wherein the university was updating its curriculum. The employees were not happy with the amount of additional work being asked of them, which might have made forming requests particularly difficult for the requesters (other researchers suggested that politeness strategies are determined mostly by the degree of imposition (BARGIELA-CHIAPPINI; HARRIS, 1996)). After the e-mail collection was complete, Bremner (2006) analysed e-mails from the university staff at the top and near the bottom of the institutional hierarchy by using Brown and Levinson's (1987) politeness theory in the analysis of interviews with the employees.

Bremner (2006) noted that the request e-mails issued by the two high position holders at the top of the university hierarchy often used rhetorical strategies and linguistic choices that were radically different from the ones used by the employees who held lower-level positions. Bremner observed that the difference in request e-mails might have been due to the inherent power that these high-level employees held, and with that they did not need to put effort into persuading 
people to follow the requests. This finding aligns with Holmes and Riddiford's (2011) study, as their participant, Helena, and her classmates were surprised when a request Helena formed in a roleplay was refused because she took on a role of a superior who would have inherent power. Lower down the hierarchy, Bremner (2006) discovered that two employees were using strategies to distance themselves from the requests by avoiding the use of personal pronouns. By drawing on the details of context in which request e-mails were written, Bremner observed that those employees were likely making such choices to assert the authority of the university and to appease other employees. Similarly, in his sample of Hong Kong professional e-mails, Kong (2006) found superiors' directives to subordinates to have more elements of politeness strategies through external modification than the directives in e-mails sent between peers. Although superiors used a high frequency of external modifications, Kong (2006) noted an institutional and formal quality present in their directives, which may serve as evidence of the superiors asserting the company's authority.

Sometimes, Bremner (2006) noted that within the same email, university employees used opposing strategies and linguistic choices. By drawing on Russell's (1997) view of context as "an ongoing, dynamic accomplishment of people acting together with shared tools" (pp. 508-509), Bremner (2006) observed that seemingly conflicting linguistic choices within the same request e-mail might be a result of a) the writer being part of multiple communities of practice (WENGER, 1998) involved in different activities, and b) the writer's intention to have the e-mail read by different audiences. Also, Bremner (2006) discovered that one of the employees was less successful with her request e-mails. She used minimal mitigation strategies and no positive face strategies. It appeared that she did not consider how the readers of her emails might perceive her, as she was an employee with responsibility but no inherent power.

Callahan (2011) also provided some context in her study to contextualize the inherent power held by two of the participants over the third one. The two male participants who had inherent power as superiors used fewer mitigation devices and wrote shorter request e-mails than the third participant, their subordinate (CALLAHAN, 2011). The provided context in this study was minimal, and no authentic data were published.

It appears that the lack of substantial descriptions of context in many studies limits our understanding of the appropriateness of the choices made by requesters. 


\section{Request E-mails}

It is important to note that while some authors refer to workplace request e-mails as a genre (e.g., HO, 2018), others refer to these e-mails as a medium (e.g., LEOPOLD, 2015). This review does not delve on this discussion and focuses on request e-mails as a type of workplace communication (text type) that exemplifies its medium (YATES; ORLIKOWSKI, 1992). While there are diverse purposes for workplace e-mail, making requests is among its top functions (GAINS, 1999) (NICKERSON, 1999) (ZIV, 1996). Nickerson (1999) found that requesting something was the most common purpose for e-mails in a corpus of 200 e-mails collected within a single international corporation. The prominence of the request e-mail in many workplaces may even grow in the future, particularly in knowledge-based economies, where sharing information is vital (HO, 2018).

\section{Oral or Written}

Many style guides for e-mail composition give prescriptive instructions that resemble older style guides for letter-writing and business communication (CRYSTAL, 2006). Gains' (1999) study found that e-mails sent to three employees of a UK insurance company appeared to follow standards for written business English, however, Gains (1999) discovered that some emails sent to four members of different UK universities took a conversational tone which more closely resembled oral discourse. E-mail resembling different media was identified as early as 1985 when Shapiro and Anderson (1985) recognized the similarities between e-mails and (a) face-to-face conversations, (b) telephone calls, (c) notes, (d) interoffice memos, and (e) written letters sent through the mail. Shapiro and Anderson (1985) declared that e-mail was a "new medium with different characteristics that cannot be treated with old rules alone" (p.10).

Research suggests that some e-mails seem to resemble oral face-to-face conversations while other e-mails more closely resemble formal written discourse (e.g., EVANS, 2012) (GAINS 1999). Studies of workplace e-mails have found instances where a single e-mail resembles both oral and written discourse (eg. GIMENEZ-MORENO, 2011), as well as e-mails whose senders alter the level of formality based on the power distance between the requester and the 
requestee (e.g., EVANS, 2012). The existence of the language of e-mail has been called into question because of the diversity of purposes and settings in which e-mail is used, which is so great that it negates the presence of any prevailing linguistic features (ANDROUTSOPOULOS, 2006).

\section{Metadiscourse and unique qualities of e-mails}

Hyland (2005) defines metadiscourse as the "aspects of a text which explicitly organize a discourse or the writer's stance to either the content or the reader" (p.14). There are two broad categories of metadiscourse: (a) interactive metadiscourse, such as transitions and code glosses, where the writer attempts to guide a reader through a text, and (b) interactional metadiscourse, such as hedges, self-mentions, and engagement markers, where the writer involves the reader in the text $(\mathrm{HO}, 2018)$. A balance of the two categories of metadiscourse is believed to be the most effective (DAFOUZ-MILNE, 2008).

Building on Hyland's (2005) research in academic writing, Ho (2018) investigated metadiscourse found in 659 authentic request e-mails written by professionals from various industries in Hong Kong and found that in this sample, professionals used interactional metadiscourse six times more frequently than they used interactive metadiscourse. This difference was much greater than in Ho's previous study on the use of metadiscourse in e-mails (HO, 2016). It appears that in various Hong Kong workplaces, interactive metadiscourse was used infrequently and the balance of metadiscourses was not used.

Since there does not appear to be any research that examined metadiscourse in oral requests in the workplace, it cannot be stated with certainty that the lack of metadiscourse balance is a unique quality of e-mails. However, there are other definite qualities that separate email from spoken face-to-face interactions. First, an e-mail can easily be sent to multiple people who have very different needs and interests (BREMNER, 2006) and second, e-mail lacks some paralinguistic qualities such as body language or facial expressions that can be witnessed in face-to-face interactions. These email qualities may result in the e-mail receiver making more effort to decipher the message, particularly if there are spelling mistakes or grammatical errors (CRYSTAL, 2006). On the other hand, the nature of e-mail allows the senders the 
opportunity to review their message and correct any errors to whatever degree they wish (CRYSTAL, 2006). Because e-mail has different qualities than oral face-to-face interactions, it would be logical to assume that the pragmalinguistic conventions used to form a request e-mail would have some differences than oral requests.

\section{Conclusion}

This literature review synthesizes research on such types of workplace communication as oral and e-mail requests. The review of the quantitative aspects of studies has provided us with the information on the frequencies of certain request strategies and mitigation devices in various workplace contexts with authentic e-mail data (CALLAHAN, 2011) (HO, 2018) (KONG, 2016) (LEOPOLD, 2015) and simulated oral data (ROSS, 2018) (WIGGLESWORTH; YATES, 2007) (YATES, 2010a). Qualitative aspects of the discussed studies have provided possible insights as to why particular pragmalinguistic conventions are used in requests (BREMNER, 2006) (HOLMES; RIDDIFORD, 2011) (LI, 2001) (YATES, 2010a). Due to the varied range of the contexts the reviewed studies took place in, and because of the difference in data type and collection methods, the findings of the reviewed studies must be understood within the specific contexts they were conducted in.

Additionally, much research on oral requests from discourse completion tasks or roleplays is conducted in simulated contexts. Simulations are merely representative of what the participants thinks they would say in a non-threatening context (RIDDIFORD; HOLMES, 2015). Yet, simulations have always been considered as a practical way to obtain oral request data as obtaining data from authentic oral requests in a workplace would prove to be quite challenging with such obstacles as privacy issues (LEOPOLD, 2015) and the workload of transcribing a corpus of authentic speech to examine just one speech act (RIDDIFORD; HOLMES, 2015). The results from the studies on oral requests in simulated contexts provide some insights on what the participants believe to be an appropriate oral request in certain workplace settings.

\section{The Research Questions}




\section{HSE}

The review presented in the paper has aimed at locating responses to the following research questions (RQs):

RQ1. What politeness strategies are found in the literature on oral requests in Englishspeaking workplaces?

Studies conducted in simulated environments suggest that NES often form oral requests in the workplace using conventionally indirect strategies and a wide variety of syntactic and lexical mitigation devices (ROSS, 2018) (WIGGLESWORTH; YATES, 2007) (YATES, 2010a). In the case of Holmes and Riddiford's (2011) study, syntactic devices appear to be especially useful for newcomers who need to make clear requests, yet still seem polite. Curiously, only one study on oral requests in the workplace mentions the word "please" which was found in $1.1 \%$ of requests within that study (ROSS, 2018). As well, grounders have been shown to serve as the most frequent external modification, which is in line with other research on oral request outside of workplace settings (FAERCH; KASPER, 1989)

RQ2. What politeness strategies are found in the literature on request e-mails in Englishspeaking workplaces?

Following Trosborg's (1995) definition of direct and indirect requests, request e-mails in the workplace discussed in this review have been often found to be direct (LEOPOLD, 2015). This may be explained by the need for clarity, as request e-mails do not have the same opportunity for paralinguistic elements as oral requests. A wide range of lexical and syntactic mitigation in request e-mails was found (CALLAHAN, 2011) (KONG, 2016). External modification in workplace e-mails is especially complex, and it appears that different contexts provide conflicting findings for how power relationships might influence a requester's use of external modification (BREMNER, 2006) (KONG, 2006). Grounders were found to be the most common type of external modification (KONG, 2006), once again confirming the findings of research conducted outside of workplace settings. It has also been observed that e-mail has particular qualities (i.e. the need for brevity, the ability to be sent from any location, and the time the email is sent differing from the time it may be read) that might influence the language used (CRYSTAL, 2006) (HO, 2018).

RQ3. Do the politeness strategies of oral request and request e-mails differ in the English-speaking workplace, and if so, what those differences are? 


\section{HSF HORIZON TES}

Oral requests and request e-mails appear to share some strategies but at different frequencies. Oral requests tend to be more indirect than e-mail requests when using Trosborg's (1995) scale of directness. The nature of e-mail (CRYSTAL, 2006) (KONG, 2006) and the potential for it to be viewed by multiple audiences likely have an influence on the requester's linguistic choices (BREMNER, 2006). In oral requests, there is an apparent lack of politeness markers that are frequently found in request e-mails, specifically, "please" and "kindly", which occur frequently in workplace request e-mails (LEOPOLD, 2015).

\section{Pedagogical Implications for workplace literacy}

Although oral requests and request e-mails in the workplace use many of the same pragmalinguistic conventions, the frequency of use of those conventions and the likely purposes of their use are different, which is another argument against referring to them as genre and indicating that the text type or type of communication is a more appropriate notion. It may be beneficial for LLs in a new workplace to learn about oral requests and request e-mails separately, as they constitute different types of communication.

Explicit teaching the pragmalinguistic conventions does not mean that LLs will be able to apply them properly; developing sociopragmatic competence through reflection on actual events, conversations and e-mails in the context of the LL's new workplace may be more beneficial. Class discussion that contextualizes such conventions may also be a useful tool, as demonstrated by Holmes and Riddiford (2011), when their main participant and her classmates realized that the egalitarian culture, typical in a New Zealand workplace context, meant that their assumptions of power relationships may not apply in a new setting. Such discussions would also allow for a chance to examine why a certain request was successful in a particular context or how to make a request more context-specific and successful.

It should also not be assumed that native speakers of a language used at work necessarily have a high level of sociopragmatic competence, as has been demonstrated in a few studies of NES reviewed in this paper. Reflection and discussion will allow for LLS to not simply mimic those around them, but to make informed appropriate choices and construct successful and appropriate requests in the workplace.

Periódico Horizontes - USF - Itatiba, SP - Brasil - e020003 


\section{HSF H O R I ON TES}

A level of directness in an oral request can cause confusion on the part of the requestee (LI, 2000), or can cause damage to the relationship between the requester and the requestee (YATES, 2010a). A learner of English might benefit from knowing common strategies and their level of directness. Oral requests in the workplace appear to commonly be conventionally indirect. Strategies NES most frequently use include apparently negotiable (WIGGLESWORTH; YATES, 2007, YATES, 2010a) and inquiring about the requestee's ability or willingness (ROSS, 2018). NES do not typically use statements of want or desire strategies when forming oral requests in the workplace (WIGGLESWORTH; YATES, 2007, YATES, 2010a, ROSS, 2018).

While the level of directness of head acts in oral requests in the workplace can lead to misunderstandings, external and internal mitigation devices also help a request to be realized and can minimize the damage to the relationship between requester and requestee. An awareness of the various mitigation devices may help a $L L$ to support a request and make it seem less abrupt and more polite. Common internal modifications to workplace request include syntactic mitigation, particularly past tense marking, use of modals, embedded if clauses, and the continuous (WIGGLESWORTH; YATES, 2007) (YATES; 2010a). NES appear to use lexical mitigation for downgraders frequently, including understaters such as "just" (WIGGLESWORTH; YATES, 2007) (YATES; 2010a). NES use of the politeness marker "please" appears to be infrequent in the workplace (ROSS, 2018), so the use of the politeness marker when forming oral requests will likely not accurately reflect how people make requests at work.

It appears that request e-mails are often more direct than oral requests in the workplace. In contrast to oral requests, imperatives are a common strategy found in the head acts of request e-mails (LEOPOLD, 2015). One method of overcoming the directness of e-mail may be to use politeness markers such as "please" which are commonly found in request emails (LEOPOLD, 2015). The use of metadiscourse may help a LL make a request e-mail's head act appear less abrupt for the requestee. As can be seen in Bremner (2006), awareness of the power dynamics may help a learner form an appropriate request. To help raise sociopragmatic awareness, it may be beneficial for students to reflect on their own and others' workplace email requests.

A curriculum that includes both pragmalinguistic conventions and sociopragmatic competence in workplace literacy training could benefit LLs. Workplace literacy training 
programs where students reflect on and discuss the pragmalinguistic conventions for facethreatening speech acts at their previous workplaces and compare them to their new workplace contexts may appear to be a useful tool to boost newcomers sociopragmatic competence (HOLMES; RIDDIFORD, 2011) (RIDDIFORD; HOLMES, 2015).

\section{Limitations}

This review has several limitations. Although oral requests are a well-researched speech act (TAGUCHI, 2015), there is currently only a small number of studies on workplace requests in English-speaking contexts. Another limitation is represented by a broad range of the settings wherein the reviewed studies took place. While trends in how requests are formed in different settings might be noted, no generalizations can be made due to the radical differences in the contexts. As pragmalinguistic conventions are used differently in different contexts (TAGUCHI, 2015) (YATES 2010a), findings of a study conducted in one simulated or authentic workplace context may not necessarily apply to another.

The different methods of data collection in the reviewed studies also limit the conclusions of this review. Privacy concerns (LEOPOLD, 2015) and the perceived impractical nature of recording authentic audio in the workplace (RIDDIFORD; HOLMES, 2015) make it difficult to obtain authentic data from the workplace. These concerns have been overcome in the studies of request e-mails but still present an obstacle for the research into oral requests in the workplace. Hence, the studies that focus on e-mail requests use mostly authentic workplace data, while the studies that focus on oral requests have been conducted mostly through simulation or through having participants recall and report how those requests were made in the workplace.

No study has investigated and compared oral and e-mail requests. Even though some quantitative studies of oral requests or request e-mails used the CCSARP Coding Manual as a general framework for coding requests, each workplace study modified the CCSARP Coding Manual creating some uncertainty, such as determining if a request is direct or indirect. Trosborg (1995) offers a remedy with her scale of directness but this scale would need to be agreed upon by most researchers and applied consistently in their investigations. 


\section{HSF HORIZONTES}

Finally, most studies considered in this review lack an adequate description of the workplace context that gives rise to the requests. Context is key in forming an understanding of why some types of communication and pragmalinguistic conventions are preferred over others. In workplace literacy training, the consideration of specific workplace contexts, in which oral requests and request e-mails are situated, would add to the new employees' understanding and use of appropriate types of communication.

\section{References}

ANDROUTSOPOULOS, J. Introduction: Sociolinguistics and computer-mediated communication. Journal of Sociolinguistics, v. 10, n. 4, p. 419-438, 2006.

AUSTIN, J. How to do things with words. 2ed. Oxford, UK: Clarendon Press, 1975.

BAKHTIN, M. The problem of speech genres. In: EMERSON, C.; HOLQUIST, M. (Eds.), Speech genres and other late essays (V. McGee, Trans., pp. 60-102). Austin: University of Texas Press, 1986.

BARGIELA-CHIAPPINI, F.; HARRIS, S. J. Requests and status in business correspondence. Journal of Pragmatics, v. 26, n. 5, p.635-662, 2006.

BIBER, D. Variation across speech and writing. Cambridge: Cambridge University Press, 1988.

BIESENBACH-LUCAS, S. Students writing emails to faculty: an examination of e-politeness among native and non-native speakers of English. Language Learning \& Technology: A Refereed Journal for Second and Foreign Language Educators, v. 11, n. 2, p. 59-81, 2007.

BLUM-KULKA, S.; HOUSE, J. Cross-cultural and situational variation in requesting behavior. In: BLUM-KULKA, S.; KASPER, G.; HOUSE, J. Cross-cultural pragmatics: requests and apologies. Norwood: Ablex Pub. Corp., 1989.

BLUM-KULKA, S.; KASPER, G.; HOUSE, J. Cross-cultural pragmatics: Requests and apologies. Norwood, N.J: Ablex Pub. Corp, 1989.

BLUM-KULKA, S.; OLSHTAIN, E. Requests and apologies: a cross-cultural study of speech act realization patterns (CCSARP). Applied linguistics, v. 5, n. 3, p. 196-213, 1984.

BREMNER, S. Politeness, power, and activity systems: written requests and multiple audiences in an institutional setting. Written Communication, v. 23, n. 4, p.397-423, 2006.

BROWN, P.; LEVINSON, S. C. Politeness: some universals in language usage. Cambridge, UK: 
Cambridge University Press, 1987.

CALLAHAN, L. Workplace requests in Spanish and English: a case study of email communication between two supervisors and a subordinate. Southwest Journal of Linguistics, v. 30, n. 1, p. 2756, 2011.

CRYSTAL, D. Language and the internet. 2. ed. Cambridge: Cambridge University Press, 2006.

DAFOUZ-MILNE, E. The pragmatic role of textual and interpersonal metadiscourse markers in the construction and attainment of persuasion: a cross-linguistic study of newspaper discourse. Journal of Pragmatics, v. 40, n. 1, p. 95-113, 2008.

EVANS, S. Designing email tasks for the Business English classroom: implications from a study of Hong Kong's key industries. English for Specific Purposes, v. 31, n. 3, p. 202-212, 2012.

FAERCH, C.; KAPER, G. Internal and external modification in interlanguage request realization. In: BLUM-KULKA, S; KASPER, G.; HOUSE, J. Cross-cultural pragmatics: requests and apologies. Norwood: Ablex Pub. Corp., 1989.

FRAGALE, A. R.; SUMANTH, J. J.; TIEDENS, L. Z.; NORTHCRAFT, G. B. Appeasing equals: lateral deference in organizational communication. Administrative Science Quarterly, v. 57, n. 3, p. 373-406, 2012.

FUKUYA, Y. J.; HILL, Y. Z. The effects of recasting on the production of pragmalinguistic conventions of request by Chinese learners of English. Issues in Applied Linguistics, v. 15, n. 1, p. 59-91, 2006.

GAINS, J. Electronic Mail - a new style of communication or just a new medium?: an investigation into the text features of E-mail. English for Specific Purposes, v. 18, n. 1, p.81-101, 1999.

GIMENEZ-MORENO, R. Register variation in electronic business correspondence. International Journal of English Studies (IJES) v. 11, n 1, p.15-34, 2011.

HALENKO, N.; JONES, C. Teaching pragmatic awareness of spoken requests to Chinese EAP learners in the UK: is explicit instruction effective? System, v. 39, n. 2, 240-250, 2011.

$\mathrm{HO}, \mathrm{V}$. Using metadiscourse in making persuasive attempts through workplace request emails. Journal of Pragmatics, v. 134, p.70-81, 2018.

HOLMES, J. (2005). 'The glass ceiling'-does talk contribute?: gendered discourse in New Zealand workplace. Paper presented at the Annual Meeting of the Australian and New Zealand Communication Association Christchurch, New Zealand, 4-7 July 2005.

HOLMES, J.; RIDDIFORD, N. From classroom to workplace: tracking socio-pragmatic 


\section{HSE}

development. ELT Journal, v. 65, n. 4, p.376-386, 2011.

. Assisting the development of sociopragmatic skills: negotiating refusals at work.

System, v. 48, p.129-140, 2015.

HYLAND, K. Metadiscourse: exploring interaction in writing. New York: Continuum, 2005.

HYLAND, K. Applying a gloss: Exemplifying and reformulating in academic discourse. Applied linguistics, 28(2), 266-285, 2007.

KONG, K. Accounts as a politeness strategy in the internal directive documents of a business firm in Hong Kong. Journal of Asian Pacific Communication, v. 16, n. 1, p.77-101, 2006.

LEOPOLD, L. Request strategies in professional e-mail correspondence: Insights from the United States workplace. TESL Canada Journal, v. 32, n.2, p.1-29, 2015.

LI, D. The pragmatics of making requests in the $L 2$ workplace: a case study of language socialization. Canadian Modern Language Review, v. 57, n. 1, p.58-87, 2000.

MURPHY, J. The settlement and integration needs of immigrants: a literature review. 2010. Disponível em: <https://olip-plio.ca/knowledge-base/wp-content/uploads/2013/03/OlipReview-of-Literature-Final-EN.pdf>. Acesso em: 21 jan. 2020.

NICKERSON, C. The use of English in electronic mail in a multinational corporation. In: BARGIELA- CHIAPPINI, F.; NICKERSON, C. Writing Business: genres, media and discourses. New York: Longman, 1999.

ROSS, A. The pragmatics of requesting in the Canadian workplace: a comparative investigation of requests presented in workplace ESL textbooks and oral discourse completion task responses. 2018. Dissertação (Mestrado em Linguística Aplicada e Estudos do Discurso). Carleton University, Ottawa, Canada.

RUSSELL, D. Rethinking genre in school and society: an activity theory analysis. Written Communication, v. 14, n. 4, p. 504-554, 1997.

SEARLE, J. R. Expression and meaning: studies in the theory of speech acts. Cambridge, UK: Cambridge University Press, 1979.

SHAPIRO, N. Z.; ANDERSON, R. H. Toward an ethics and etiquette for electronic mail. Santa Monica: RAND Corporations, 1985.

STREET, B. What's "new" in New Literacy Studies? Critical approaches to literacy in theory and practice. Current issues in comparative education, 5(2), 77-91, 2003. 


\section{USF HORIZONTES}

SYKES, J. Learner request in Spanish: examining the potential of multiuser virtual environments for L2 pragmatics acquisition. In: LOMIKA, L; LORD, G. The second generation: online collaboration and social networking in CALL. San Marcos: CALICO, 2009.

TAGUCHI, N. Instructed pragmatics at a glance: where instructional studies were, are, and should be going. Language Teaching, v. 48, n. 1, p. 1-50, 2015.

TROSBORG, A. Interlanguage pragmatics: requests, complaints and apologies. Berlin: De Gruyter, 1995.

TROSBORG, A. Rhetorical strategies in arbitration law. Legal discourse across cultures and systems, 1, 199, 2008.

WENGER, E. Communities of practice: learning, meaning, and identity. Cambridge: Cambridge University Press, 1999.

WIGGLESWORTH, G.; YATES, L. Mitigating difficult requests in the workplace: what learners and teachers need to know. TESOL Quarterly, v. 41, n. 4, p.791-803, 2007.

YATES, L. Dinkas down under: request performance in simulated workplace interaction. Pragmatics and Language Learning, v. 12, p. 113-140, 2010a.

YATES, L. Speech act performance in workplace settings. In: MARTíNEZ-FLOR, A.; USÓ-JUAN, E. Speech act performance: theoretical, empirical and methodological issues. Philadelphia: John Benjamins Publishing, 2010b.

ZIV, O. Writing to Work: how using email can reflect technological and organizational change. In: HERRING, S. C. (Ed.). Computer-Mediated Communication: linguistic, social and crosscultural perspectives. Amsterdam: John Benjamins, 1996.

Recebido em outubro de 2019.

Aprovado em dezembro de 2019. 